protective, which may signify a greater deterrent effect. However, it is unclear if the apparent risk reduction will be long-lasting and we cannot exclude the possibility that this finding may reflect biases relating to social desirability or concerns relating to risk of prosecution.

\section{PREVALENCE OF BEHAVIOURAL RISK FACTORS FOR ROAD TRAFFIC INJURIES: REGIONAL DIFFERENCES IN BRAZIL}

${ }^{1}$ Katharine A Allen, ${ }^{2}$ Flavio Cunto*, ${ }^{3}$ Gabriel Andreuccetti, ${ }^{2}$ Manoel Neto, ${ }^{3}$ Vilma Leyton, ${ }^{3}$ Daniele Sinigawa, ${ }^{3}$ Heralcito Carvalho, ${ }^{1}$ Shirin Wadhwaniya, ${ }^{1}$ Adnan A Hyder. ${ }^{1} J o h n s$ Hopkins School of Public Health, Baltimore, USA; ${ }^{2}$ Department of Transportation, Federal University of Ceara, Brazil; ${ }^{3}$ Faculty of Medicine, University of Sao Paulo, Brazil

\subsection{6/injuryprev-2016-042156.642}

Background Road traffic injuries (RTIs) are estimated to be the fourth leading cause of death in Brazil. This burden is not uniform throughout the country with differences between the wealthy developed South and less-developed North. Understanding regional differences in specific behaviours (speeding, helmet use, seatbelt use and drink driving) associated with RTIs is critical in designing effective RTI interventions. This study aimed to assess such differences by comparing observed road safety behaviours in the cities of Sao Paulo (South) and Fortaleza (North).

Methods As part of the Bloomberg Initiative for Global Road Safety (BIGRS), observational studies were conducted in Sao Paulo and Fortaleza, Brazil. Six sites were randomly selected in each city and trained observers recorded road safety behaviour (speeding, helmet use, seatbelt use and drink driving) for three full-day periods between August-October 2015.

Results 190,730 observations were collected: Sao Paulo $(113,539)$, Fortaleza $(77,191)$. Fortaleza had higher rates of speeding (16.7\%) with motorcycles being the most common speeders compared to Sao Paulo (8.1\%) where sedans were most responsible. Rates of seatbelt and helmet use among all passengers were higher in Sao Paulo (90.2\% and 99.1\%, respectively) than Fortaleza (63.4\% and $82.8 \%$, respectively). Drivers testing positive for any alcohol was higher in Sao Paulo (14\%) than Fortaleza (1.2\%).

Conclusions Important regional differences in road safety behaviour highlight the need for tailored interventions in Brazil. National-level interventions might not be as effective as regional ones. While both cities had high rates of helmet use, seatbelt use remains low in Fortaleza. Speeding, especially among motorcycles, is a priority for Fortaleza and parts of Northern Brazil. Sao Paulo's alcohol results illustrate the urgency for drink driving-based interventions for areas of Southern Brazil. These results will be used to develop specific interventions for BIGRS.

\section{3 CORRELATION OF ROAD SAFETY PERFORMANCE WITH SOCIAL AND ECONOMIC INDICATORS IN THE EUROPEAN UNION}

George Yannis, loannis Zantiris. National Technical University of Athens

10.1136/injuryprev-2016-042156.643

Background - methodology The objective of this research is the correlation of road fatalities with basic social and economic indicators in the European Union. On that purpose, a database was developed containing the most recent data regarding population, road fatalities, gross domestic product per capita, human development index, unemployment rate and few other economic and social indicators for the twenty eight Member States of the European Union. Statistical models were developed using the method of multiple linear regression and applied for all countries tested but also for different groups of countries selected (northwestern, eastern, southern countries).

Results The application of the models demonstrated that annual increase of GDP, unemployment rate and suicides rate leads to annual increase of road fatalities. Whereas road fatalities annual decrease is correlated to increase of the human development index and of the motorway network density. These results are broadly confirmed with some variations in the three groups of EU countries.

The sensitivity analysis demonstrated that the human development index has the most important effect on road fatalities annual change

Conclusions The findings of this research might be useful for decisions makers to identify the expected level of road safety in a region or in a country based on their macroscopic economic and social indicators, allowing thus to identify the separate effect of specific road safety policies, programmes and measures implemented.

\section{NEW AND INNOVATIVE WAY TO TACKLE CHILD SEXUAL ABUSE - WWW.OTANVASTUUN.FI}

Jenni Häikiö, Veera Uusoksa. Save the Children Finland, Finland

\subsection{6/injuryprev-2016-042156.644}

Background Child sexual abuse is a serious safety and health issue. To prevent the sexual abuse of children, it is crucial to target individuals who run the risk of conducting a sexual crime against a child but have not (yet) done so. There are treatment programs in Finland within prison services for sex offenders, but no specialised interventions exist for potential offenders.

Methods The www.otanvastuun.fi online self-help material developed by Save the Children Finland, targets specifically potential child sexual offenders and focuses on their online behaviour. The website is based on the English-speaking croga. org material, and draws on best practices of sex offenders treatment programmes and interviews with convicted sex offenders, who have been actively involved in the development of the material. The aim of the website is to increase the self-awareness of the potential offenders and to help them to control their problematic behaviour.

Results Since the publication of the material, there have been nearly 15000 visitors on the website. The material has been introduced at several occasions, and has been well received by the professionals working with convicted and potential sex offenders and by other relevant parties and audiences. A systematic evaluation of the website among sex offenders and professionals working with them is scheduled early next year. The Otanvastuun.fi website has been awarded the Finnish national crime prevention prize 2015 and represents Finland at the annual European crime prevention competition.

Conclusions To prevent child sexual abuse, it is crucial to target potential offenders. The Otanvastuun.fi online self-help material targets individuals, who have not (yet) acted in illegal or harmful ways towards children but are at risk of doing so. The material has been well received by the main target groups and other relevant parties and audiences, and has been awarded the Finnish national crime prevention prize. 